\title{
A gestão participativa na escola
}

\author{
La gestión participativa en la escuela \\ Participatory management in school
}

\begin{abstract}
Alexsandro Rúdio Broetto ${ }^{1}$ Laudinéia Maria Neves Dias Rúdio²

\section{Resumo}

O livro: A Gestão Participativa na Escola de Heloisa Luck reúne um conjunto de informações sobre gestão participativa na escola e se assenta no entendimento de que o alcance dos objetivos educacionais, em seu sentido amplo, depende da canalização e do emprego adequado da energia dinâmica ocorrente no contexto de sistemas de ensino e escolas em relação a objetivos educacionais concebidos e assumidos por seus membros, de modo a constituir um empenho coletivo em torno da sua realização.
\end{abstract}

Palavras-chave: Gestão Participativa; Escola; Sistemas de Ensino.

\section{Resumen}

El libro: La Gestión Participativa en la Escuela de Heloisa Luck reúne un conjunto de informaciones sobre gestión participativa em la escuela y se asienta em el entendimiento de que el alcance de los objetivos educativos, em su sentido amplio, depende de la canalización y del empleo adecuado de la energia dinâmica ocurrida em el contexto de sistemas de enseñanza y escuelas em relación a objetivos educativos concebidos y asumidos por sus miembros, para constituir un compromisso colectivo en torno a su realización.

Palabras clave: Gestión Participativa; Escuela; Sistemas de Enseñanza.

\begin{abstract}
The book: Participatory Management in the School of Heloisa Luck brings together a set of information on participatory management in school and is based on the understanding that the achievement of educational objectives, in its broad sense, depends on the channeling and appropriate use of the current dynamic energy in the context of educational systems and schools in relation to educational objectives conceived and assumed by its members, in order to constitute a collective commitment to its realization.
\end{abstract}

Keywords: Participatory Management; School; Teaching Systems.

LUCK, Heloisa. A Gestão Participativa na Escola. Saraiva, 2016. 126 p. v. 3. (Série Cadernos de Gestão).

\footnotetext{
${ }^{1}$ Mestre pela Faculdade UNIDA (2017) de Vitória, graduado em DIREITO pela Universidade Vila Velha (2012), atuando como advogado cível e criminal. Professor de Direito, História, Filosofia, Sociologia, Antropologia, Psicologia e de Ciências da Religião. E-mail: rudioadv@gmail.com.

${ }^{2}$ Graduada em Enfermagem - Licenciada em Biologia. MESTRE em Ciências da Educação. E-mail: laudineia_dias@yahoo.com.br.
} 


\section{Introdução}

O livro analisado reúne um conjunto de informações sobre gestão participativa na escola e se assenta no entendimento de que o alcance dos objetivos educacionais, em seu sentido amplo, depende da canalização e do emprego adequado da energia dinâmica ocorrente no contexto de sistemas de ensino e escolas em relação a objetivos educacionais concebidos e assumidos por seus membros, de modo a constituir um empenho coletivo em torno da sua realização. São 216 páginas no total.

O livro é introduzido mostrando o cenário da educação brasileira que tem passado por algumas mudanças significativas. Apresenta-se, aquelas ocorridas no campo legal, tendo como espinha dorsal a Constituição Federal de 1988. Esta possibilitou desdobramentos legais relevantes para a educação básica que levaram, entre outras, a: mudanças na organização e estrutura curricular, na sistemática de financiamento, no processo de gestão dos sistemas de ensino e na ampliação do acesso à escola básica.

O diferencial deste livro, se comparado a outros com esta mesma temática, está na abordagem que procura articular com as reflexões teóricas e situações concretas, ajudando o gestor no processo de enfrentamento dos problemas com os quais se deparam no cotidiano escolar.

O livro apresenta uma reflexão sobre os resultados dos estudos efetivados a partir de vivencias e observações da autora sobre o cotidiano da gestão escolar, propondo soluções através do diálogo.

O livro fala da aplicação do planejamento sistematizado em escolas públicas e privadas, possui uma conotação política em termos de compromisso com a formação do cidadão para um tipo de sociedade e também pedagógica, uma vez que possibilita ao leitor, principalmente ao gestor, identificar aspectos que poderão ser válidos para a sua atuação na escola.

O diálogo é apresentado no livro como uma forma de chagar a um consenso acerca das ações a serem tomadas pela comunidade escolar. Cita autores como Veiga (1998), quando fala sobre a dimensão pedagógica das ações educativas da escola, visando à efetivação de seus propósitos e sua intencionalidade. Para a autora, a dimensão política se cumpre na medida em que ela se realiza enquanto prática especificamente pedagógica.

\section{Desenvolvimento}


O livro mostra que a escola espera da família uma participação efetiva na vida escolar dos filhos e o apoio às ações da escola, manifestados através de críticas e sugestões para a melhoria do nosso trabalho, da atenção às necessidades do filho que muitas vezes não está na simples ajuda nas atividades, mas no diálogo aberto e nas manifestações afetivas.

Fala na gestão democrática, a qual é fundamental para a definição de políticas educacionais que orientam a prática educativa, bem como revitaliza os processos de participação, dentro dos parâmetros definidos no "chão" da escola pública e é um canal no processo de democratização, na medida em que reúnem diretores, professores, funcionários, estudantes, pais e outros representantes da comunidade para discutir, definir e acompanhar o desenvolvimento do Projeto Político-Pedagógico da Escola.

A autora mostra que muitos desafios estão por vir, mas com certeza este é um importante passo para garantir a efetiva participação das comunidades escolar e local na gestão das escolas, contribuindo, assim, para a melhoria da qualidade social da educação para todos.

A autora enfatiza que cabe a escola, repensar o seu papel na formação de verdadeiros cidadãos, caminhando nesta direção com seriedade, como compromisso da coletividade e, nesta busca, os gestores devem fazer frente, através de uma constante revisão crítica de seu papel, envolvendo toda a comunidade escolar, consciente do seu compromisso na conquista de uma nova escola, que seja verdadeiramente democrática. Somente com estas prerrogativas a escola pode realmente se tornar um fator de cidadania.

Aborda sobre os princípios que devem nortear a construção do Projeto PolíticoPedagógico: relação escola x comunidade, democratização do acesso e da permanência do aluno na escola com sucesso, democracia, autonomia, qualidade de educação para todos, organização curricular e valorização dos profissionais da educação, são interligados e complementares entre si.

A autora entende que a educação deve estar preocupada em preparar o cidadão para conhecer a si mesmo, e depois se torna mais fácil entender a sociedade, tornando um ser pensante e participativo ante os acontecimentos da sociedade. Se o Projeto PolíticoPedagógico serve como bússola na educação, o mesma precisa direcionar o estudante rumo a uma aprendizagem de qualidade.

O livro aborda sobre a necessidade de otimizar a qualidade educativa das escolas a partir de uma gestão eficiente e eficaz. Destaca que o princípio de gestão democrática implica repensar a estrutura de poder da escola, tendo em vista que a prática da participação coletiva 
atenua o individualismo, pois implementa mecanismos e estratégias que favorecem ampliação da solidariedade e superação da opressão.

Mostra a real situação das políticas educacionais brasileiras dos últimos 30 anos, as quais admitem o modelo de gestão descentralizada, com a participação dos usuários na formulação de propostas para o desenvolvimento da gestão educacional e o reconhecimento da função estratégica do diretor da escola.

Em suma, o livro mostra que a participação deve ser encarada como um fator de coesão e consenso, tornando-se necessário repensar a estrutura de poder da escola, tendo em vista que a prática da participação coletiva atenua o individualismo, ampliar a solidariedade, superar a opressão e anular a dependência de órgãos intermediários que elaboram políticas educacionais das qual a escola é mera executora.

\section{Conclusão}

A autora conclui o livro enfatizando acerca das melhorias que podem ser efetivadas na escola a partir da abertura de espaços para que toda a comunidade escolar participe, dê sugestões, atue de modo ativo e participativo. Ela acredita que os pais devem participar mais do processo escolar e que eles podem contribuir significativamente para a ampliação da qualidade do ensino, isto dependerá da motivação que a própria escola pode oferecer através da realização de parcerias entre escola e família.

\section{Referências}

LUCK, Heloisa. A Gestão Participativa na Escola. Saraiva, 2016. 126 p. v. 3. (Série Cadernos de Gestão). 